\title{
O texto-performance como tentativa de exuzilhamento
}

\section{The text-performance as an attempt at exuzilhamento}

\author{
Naiene Sanchez Silva a,* \\ Thais Pereira da Silva a
}

RESUMO: Trata-se da relatoria crítica da primeira sessão de palestras do encontro "Decolonilalidade e Ciência da Informação: veredas dialógicas" que contou com as intervenções "Exuzilhar saberes: informações, tecnologias e pluriepistemologias" de Maria Aparecida Moura e "Tempo, memória e documentos" de Bianca Santana.

Palavras-chave: Texto-performance; Enxuzilhamento; Ciência da Informação.

ABSTRACT: This is the critical report of the first session of lectures of the meeting "Decolonilalidade e Ciência da Informação: veredas dialógicas " which included the interventions " Exuzilhar saberes: informações, tecnologias e pluriepistemologias" by Maria Aparecida Moura and "Tempo, memória e documentos" by Bianca Santana.

Keywords: Text-performance; Enxuzilhamento; Information Literacy.

a Programa de Pós-Graduação em Ciência da Informação, Universidade de São Paulo, São Paulo, SP, Brasil.

*Correspondência para/Correspondence to: Naiene Sanchez Silva. E-mail: naiene@usp.br.

Recebido em/Received: 24/06/2021; Aprovado em/Approved: 13/10/2021.

Artigo publicado em acesso aberto sob licença CC BY 4.0 Internacional @(i) 


\section{INTRODUÇÃO}

Após ser apresentada ao tema da decolonialidade, foi inevitável não pensar em novos formatos e rever os conteúdos das minhas produções acadêmicas. A proposta aqui apesentada é fruto dessas revisões.

Movida pelo desejo de ver o mundo de uma maneira menos ocidentalizada, propus que a relatoria crítica da primeira sessão de palestras do encontro "Decolonilalidade e Ciência da Informação: veredas dialógicas" seja feita em formato de textoperformance. A metodologia do que denominei como texto-performance consiste na elaboração de uma relatoria crítica de minha autoria que passará pela análise de uma colega que, assim como eu, atua no campo da Ciência da Informação.

Convidei Thais Pereira para realizar essa performance comigo. Quando decidi fazer dessa relatoria crítica um texto-performance, pensei imediatamente em convidá-la. Conheci Thais recentemente e foi ela que me apresentou a obra de bell hooks. A ideia é que Thais aponte os valores coloniais presentes no meu texto. Para isso, podem ser feitas rasuras, destaques, comentários, desenhos, intervenções de qualquer natureza dentro do texto que entreguei a ela. Após a interferência de Thais, o texto seguirá para publicação. Optei, na maior parte do texto, em não apagar os escritos da Naiane Sanchez, mas construir, a partir do conceito exuzilhamente, o texto conjuntamente, não apaziguando os conflitos, os dissensos, os consensos e os questionamentos de cada uma de nós.

A primeira sessão de palestras do encontro Decolonilalidade e Ciência da Informação: veredas dialógicas" contou com as intervenções "Exuzilhar saberes: informações, tecnologias e pluriepistemologias" de Maria Aparecida Moura e "Tempo, memória e documentos" de Bianca Santana. A mediação foi feita por Cayo Honorato. O textoperformance que será apresentado inspirou-se no tema da exuzilhada, abordado na conferência de Maria Aparecida Moura. O conceito de exuzilhada deriva da ideia de encruzilhada e aqui entendido como o ponto de encontro entre diferentes culturas dentre as quais destacam-se as narrativas de matrizes africanas, capazes de ampliar a maneira como enxergamos o mundo.

Para Leda Martins, a encruzilhada é um termo teórico utilizado para melhor compreender hibridações que resultam das dinâmicas culturais. Por intermédio do conceito de encruzilhada é possível analisar “(...) processos inter e transculturais, nos quais se confrontam e se entrecruzam, nem sempre amistosamente práticas performáticas, concepções e cosmovisões, princípios filosóficos e metafísicos, saberes diversos, enfim" (MARTINS, 2002, p.73).

O objetivo é que este texto-performance seja um exercício apto a inaugurar um espaço que esteja em consonância com a ideia de encruzilhada. Segundo Martins, é o local da ação performática “(...) é lugar radical de centramento e descentramento, intersecções e desvios, texto e traduções, confluências e alterações, influências e divergências, fusões e rupturas, multiplicidade e convergência, unidade e pluralidade, 
origem e disseminação" (MARTINS, 2002, p.73). Como o terceiro espaço, a encruzilhada é o local dos novos significados e sentidos plurais.

Creio que não se trata apenas de reconhecer que os não brancos foram silenciados, trata-se de criar possibilidades de incluir essas vozes em nossas vidas de maneira radical e performática. É possível que o ímpeto e a força da obra de arte nos indiquem caminhos nesse sentido. Grada Kilomba defende a ideia de que é preciso experimentar outros formatos acadêmicos para exercer a descolonialidade. Segundo a artista, a visão das irmãs brancas é distinta da visão das irmãs negras.

É evidente que as minhas questões, sendo uma mulher Negra, devem diferir das questões das colegas brancas. Os temas, os paradigmas e metodologias usadas para explicar minha realidade podem diferir desde os temas, paradigmas e metodologias do grupo dominante. Por outro lado, isso não significa que eu sou incapaz de produzir conhecimento, mas que o conhecimento que eu produzo transgride o academicismo tradicional. Quando eu escrevo, eu descolonizo a academia, transformo as configurações de conhecimento e poder. Cada sentença e cada palavra abre um novo espaço para discursos alternativos e políticas do conhecimento. Isso é a descolonização do conhecimento.

Esse texto-performance não é o resultado da reflexão sobre o rumo da minha atuação dentro do campo da Ciência da Informação. Trata-se de lidar com a possível tirania que há no modo como vejo o mundo. Talvez o texto-performance pode ser uma nova forma (transgressora) metodológica-teórica de produzir conhecimento decolonial?

\section{EXUZILHAR SABERES: INFORMAÇÕES, TECNOLOGIAS E PLURIEPISTEMOLOGIAS}

\section{Maria Aparecida Moura'}

O rito, como prática religiosa, tem a função de relembrar o passado. A cerimônia ritualística possibilita aos seus participantes uma conexão com a ancestralidade, seja com divindades de um tempo passado ou com pessoas que já morreram. É por intermédio do rito, portanto, que a religião inaugura uma maneira peculiar de organizar o tempo. Praticada de formas diferentes, a religião é uma forma de cultura que acompanha os seres humanos desde a pré-história até os dias de hoje. Acredito que, é esta definição do conceito de rito que orienta a experiência proporcionada pela fala da professora Maria Aparecida Moura.

A palestra Intitulada "Exuzilhar saberes: informações, tecnologias e pluriepistemologias", tornou-se rito quando, antes de iniciar sua exposição, no encontro "Decolonialidade e Ciência da Informação: veredas dialógicas”, Moura opta

\footnotetext{
${ }^{1}$ Maria Aparecida Moura é professora titular da Universidade Federal de Minas Gerais (UFMG) e possui pós-doutorado em Semiótica Cognitiva e Novas Mídias pela Maison de Sciences de I' Homme, doutorado em Comunicação e Semiótica pela Pontifícia Universidade Católica de São Paulo (PUC), mestrado em Educação pela UFMG e graduação em Biblioteconomia.
} 
por apresentar um trecho do documentário "Raiz Afro Mãe" em que o Mestre Moa do Katendê canta a música "Exu é Lebara".

A exibição do vídeo pareceu, de alguma maneira, presentificar Mestre Moa do Katendê. Essa experiência levou-me a pensar que todas as pessoas que seriam mencionadas durante a palestra influenciam não só a pesquisa acadêmica, mas também a vida de Moura. Não se trata de atribuir crédito aos autores e às suas respectivas teorias, trata-se de reconhecer o legado ancestral que conecta os ouvintes, a professora Moura, Mestre Moa do Katendê, Sueli Carneiro, Cidinha Silva, Achille Mbembe e Leda Martins. O início da conferência provocou-me a refletir sobre a maneira como lido com os autores que compõem o referencial teórico das pesquisas acadêmicas que desenvolvo e sobre qual a importância que atribuo a questão da ancestralidade em minha vida.

Moura propôs que pensássemos o tempo e o espaço na perspectiva da ancestralidade, para isso, a professora fez uso do termo cunhado por Cidinha da Silva: exuzilhar. Para explicar a ideia de exuzilhamento, Moura esclareceu que, no candomblé, Exu é o mediador entre o òrun (o céu) e o àiyé (a terra)², ele é o orixá mensageiro que se ocupa da comunicação entre o humano e o divino, é o deus possuidor de Poder. Na esteira desse pensamento, exuzilhar é um conceito criado a partir da fusão entre o nome de um orixá, no caso Exu, e a ideia de encruzilhada. Lembrei-me que Exu faz das encruzilhadas a sua morada, é ali que nasce o seu poder e a sua habilidade de comunicação entre homens e mulheres e as divindades. O verbo exuzilhar pode ser entendido como a ação de aproximar as diferentes culturas, os saberes populares e a ciência moderna, as tradições e as contemporaneidades, trata-se de privilegiar as pluriepistemologias em vez de apenas priorizar as epistemologias hegemônicas.

Moura qualificou a colonialidade como uma ideia rançosa e grudenta, capaz de nutrir relações íntimas, discretas e, por vezes, explícitas com a informação e com as formas de produzir conhecimento. Nesse sentido, a Ciência da Informação (Cl) não escapa e por vezes reproduz os princípios colonizadores, até porque o campo "surgiu e se insere em contexto de apaziguamento dos estranhamentos", como bem observou a professora, o que não cabe nos processos de decolonialidade. Ela destacou a necessidade de combater com força política a influência de valores coloniais no campo da informação, o que implica em uma reflexão profunda sobre o que $\mathrm{Cl}$ produz, analisa e dissemina.

A constatação da professora fez-me lembrar da brutalidade investida contra o Mestre Moa do Katendê. Aos que não se recordam, Mestre Moa do Katendê foi violentamente assassinado após declarar sua intenção de voto durante as eleições de 2018. Lembrome que, na época, os veículos de comunicação noticiaram que a tragédia aconteceu pelo fato de Mestre Moa do Katendê ter se posicionado contra uma determinada corrente política. No entanto, penso que o motivo do crime não se limitou a divergência política como foi divulgado pelos veículos de comunicação. Dentre os

\footnotetext{
${ }^{2}$ Nas tradições e na mitologia ioruba, o òrun é o céu, ou seja, o mundo espiritual e o lar dos orixás, os deuses nagôs. Já o àiyé é a Terra, o mundo físico.
} 
valores coloniais que estão em jogo nessa tragédia não foi mencionada a herança escravocrata que naturaliza a violação do corpo negro.

Moura sugeriu que a Ciência da Informação deve agenciar a pauta decolonial. Ela também concluiu que o poder é o ponto de convergência entre a decolonialidade e a entidade Lebara, mencionada na canção interpretada por Mestre Moa do Katendê. Levando em consideração essas afirmações, de que maneira o campo da Ciência da Informação lida com o poder proveniente da decolonialidade? Pensando que essa é uma batalha a ser enfrentada no terreno da política, como a Ciência da Informação pode fazer este enfrentamento?

Certamente, ao longo das falas do encontro "Decolonialidade e Ciência da Informação: veredas dialógicas", essas perguntas foram respondidas. No entanto, será que devemos acreditar na superação dessas perguntas, ou seria justamente o permanente exercício de revisitar esses questionamentos, um dos reflexos daquilo que Moura chama de poder da decolonialidade?

Segundo a professora, em nome de um compromisso com o valor da imparcialidade, a Ciência da Informação hierarquizou culturas e consagrou modelos avessos ao tema da decolonialidade. Foi, portanto, em nome de uma suposta neutralidade que a Ciência da Informação desenvolveu critérios de objetividade que resvalam em valores colonizadores. A Ciência da Informação passou a reconhecer a sua atuação ambígua recentemente. Esse cenário justifica a urgência em ampliar a quantidade de objetos analisados, estimular o estudo de novos objetos, dialogar com outros saberes e aplicar novas metodologias, aumentando a capacidade crítica, além de potencializar o conhecimento produzido no campo. Da mesma forma, faz-se necessário ao campo abrir-se cada vez mais para novos sujeitos, que por muito tempo ficaram às margens das instituições de ensino e que agora reivindicam seus lugares nas universidades como sujeitos cognoscentes e não mais como objetos de pesquisa.

Após relatar essas arbitrariedades do campo, Moura sustentou que a Ciência da Informação deve agir no terreno da exuzilhada para reverter esse cenário, como uma ferramenta para produção de conhecimento decolonial, a fim de descentralizar a produção e a disseminação da informação e do conhecimento, reconhecendo outras epistemologias, cosmovisões, línguas e culturas sem hierarquizá-los, rompe com os poderes estabelecidos, na qual a raça, de acordo com Quijano, tem papel central, pois é definidora das colonialidades do ser, do saber e do poder, que contribui para as desigualdades que atravessam as experiências de vidas de mulheres e homens negros e indígenas: simbólicas e socioeconômicas.

A intervenção de Moura denunciou o mercado da informação dominado por poucas e poderosas empresas de tecnologia. Segundo a professora, a pandemia da COVID-19 serviu para revelar de maneira contundente como as corporações que dominam o mercado da informação colocaram em prática um sistema de valores que naturaliza a 
lógica colonial³. Moura explicou que essas empresas valorizaram respostas rápidas em detrimento do tempo da experiência humana. Além disso, uma fala da professora chamou a minha atenção e tem sido um tema importante de debate: o racismo algorítmico das plataformas digitais ${ }^{4}$, por isso destaco que rapidez das respostas, estabelecidas a partir dos paradigmas hegemônicos, restringem a diversidade de fontes de informações, a pluralidade de vozes e o contraditório, assim o modus operandi dessas corporações, a GAFA (Google, Apple, Facebook e Amazon), moldam um mundo branco e silenciam as alteridades.

O tema da influência das empresas de tecnologia, levou-me a pensar que, se por um lado, a rapidez exige padrões pré-estabelecidos, por outro lado, a experiência humana exige um tempo que não pode ser determinado por padrões. O lucro dessas empresas é definido por um simulacro de experiência que depende da padronização do tempo.

Ainda sobre esse tema, surgem-me as dúvidas: seria possível mensurar os estragos fomentados pela cultura algorítmica? Como sincronizar nosso processo de análise ao tempo desenfreado da cultura algorítmica? É possível construir uma cultura algorítmica alicerçada sobre valores decoloniais?

Creio que os fenômenos culturais indicam que, na maioria das vezes, o sucesso econômico determina os processos de valorização simbólica. Ao mesmo tempo que podemos pensar que a superestrutura (o simbólico) legitima a infraestrutura (a estrutura econômica). Em outras palavras, a cultura exerce um papel importante para validar lógicas econômicas e sistemas políticos. Sueli Carneiro, como apontou Moura, embasada em Foucault, enfatiza que existe um dispositivo de racialidade atuando no país, ditos (enunciados científicos e discursos) e não ditos (instituições, organizações arquitetônicas), que conformam o racismo estrutural. Penso ainda que, não raro, em decorrência da herança colonizadora, sistemas simbólicos de origem africana são alvos de um processo de desvalorização. Essa atitude colonizadora pode gerar, aquecer e reforçar processos ideológicos que retroalimentam o mercado e contribuem para definir as experiências das vidas negras e desumanizando-as.

A intervenção de Moura terminou do mesmo modo como começou, isto é, com música. A artista coreográfica e imagética Ana Pi (filha de Moura) apresentou a obra What we are speaking about / from Grada Kilomba in Decolonizing Knowledge - 2016. Ana Pi deu voz ao texto de Grada Kilomba, outra artista cuja obra tem como tema a decolonialidade. A performance da artista termina com os seguintes questionamentos

3 Nunca é demais lembrar que a Apple vale mais que o PIB do nosso país: https://www.uol.com.br/tilt/ultimas-noticias/estado/2020/08/06/avaliada-em-us-188-trilhaoapple-supera-o-pib-do-brasil.htm

${ }^{4}$ O pesquisador Tarcízio Silva é um dos especialistas no tema no país, sendo autor de alguns livros sobre o racismo algorítmico. Disponível em < https://www.geledes.org.br/racismoalgoritmico-pesquisador-mostra-como-os-algoritmos-podemdiscriminar|?gclid=CjoKCQjwuL_8BRCXARIsAGiC51BCHLhVBOcBaHxJzSCQDjW6APtfJUfQdwdWOoKRG7_-PspmweoRpUaAsbfEALw_wcB > Acesso em 20 out 2020. 
e um forte posicionamento decolonial: "Quem pode falar? Do que podemos falar? Descolonize seu conhecimento".

\section{TEMPO, MEMÓRIA, DOCUMENTOS}

\section{Bianca Santana 5}

A pensadora Bianca Santana iniciou sua fala intitulada "Tempo, memória, documentos" apresentando distintas definições sobre o conceito de tempo, destacando o processor colonizador que é a concepção linear. Durante sua explanação, Santana destacou que existem culturas que não entendem o tempo de maneira linear. A reflexão inicial de Santana possibilitou-me constatar que, ao instituir padrões, são negligenciadas outras possibilidades de entender o mundo do qual faço parte.

Ora, se há diversas maneiras de entender o tempo, por que devo considerar exclusivamente a possibilidade de que houve um passado, há um presente e haverá um futuro? Essa maneira de ver o tempo, tão introjetada na vida da maioria dos cidadãos do planeta, deflagra o predomínio de uma determinada cultura sobre outras. Ao instituir um padrão sobre a percepção do tempo deixo de conhecer e reconhecer a legitimidade de outras formas de pensar.

Santana, assim como Moura, mencionou Exu em sua fala. Santana resgatou a mitologia iorubá e apresentou Exu como um orixá que transcende a ideia do tempo linear. Para compreender essa faceta do orixá, a pensadora mencionou o episódio iorubá no qual "Exu matou um pássaro ontem, com a pedra que arremessou hoje". Ao interpretar essa passagem, Santana fundamentou-se na teoria de Muniz Sodré e explicou que a ação de Exu inventa o tempo.

Vale destacar que a palestrante não se limitou a explicar a percepção do tempo exclusivamente a partir da cultura iorubá, houve um esforço em abordar o ponto de vista de diversas culturas que caminham na contramão da compreensão linear de tempo.

Dessa forma, Bianca Santana lembrou da cultura dos bantus, os primeiros povos africanos que foram escravizados e trazidos para Abya Yala ${ }^{6}$, mais precisamente para Pindorama, em uma das línguas tupi, que significava Terra das Palmeiras e hoje recebe o nome de Brasil. Para o candomblé de Angola, como explicou a palestrante, o Nkisi Kindembu é o Rei do Tempo, que é representado por uma bandeira branca hasteada de baixo de uma árvore, as raízes conectam-se à ancestralidade e à terra, já as folhas e

5 Doutora em Ciência da Informação pela Escola de Comunicações e Artes (ECA) da Universidade de São Paulo e Mestre em Educação também pela USP, Bianca Santana é formada em Jornalismo e é autora do livro "Quando me descobri negra". Atualmente, escreve a biografia da Sueli Carneiro.

${ }^{6}$ É o nome da América na língua Kuna, um dos povos originários do continente, que significa Terra Viva. 
os galhos estão em conexão com ar, o próprio tempo. Para os bakongos, pertencentes à etnia bantus, o tempo, em minúsculo, significa aquele que permite o desenrolar da vida e é cíclico, não linear. Ademais, possui duas dimensões: a concreta e abstrata. A primeira refere-se à experiência concreta de vida do ser humano. Já a segunda, não há começo, meio e fim, está nas mãos do poder supremo, cósmico. Santana nos lembrou que, como parte do universo, nós também somos o tempo. O cosmograma dos bakongos, o Diekenga, é um círculo que apresenta os quatro ciclos da vida, segundo o filósofo congolês Bunseki Fu-Kiau: o nascimento e o amadurecimento, a concepção e a morte.

Figura 1. Cosmograma Bakongo, o Diekenga.

\section{Cosmograma Bakongo}

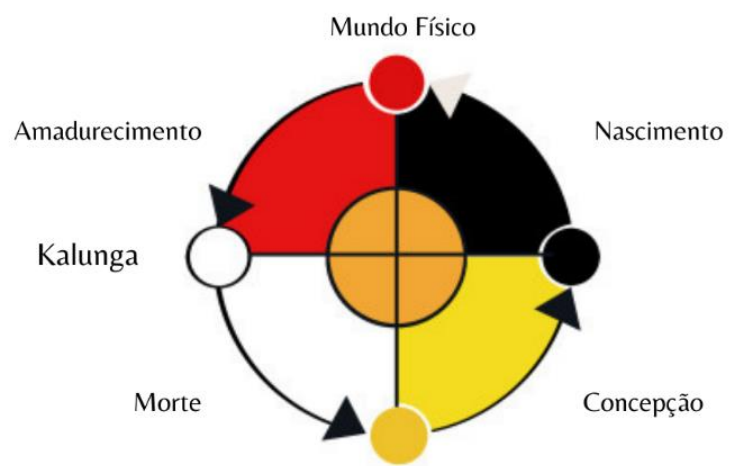

Mundo Espiritual

No Brasil, a concepção de tempo dos bantus encontra-se com as dos povos iorubás, tupinambás, krenak, tucanos, além das europeias. Santana comentou sobre a existência de um entrelugares, isto é, um lugar afro-brasileiro. Nessa perspectiva, o lugar afro-brasileiro é um entre-lugares, sendo uma teia entre tempos, uma trança entre o inédito e a repetição. Em outras palavras, é a própria exuzilhada. A ancestralidade conecta-se ao tempo presente pelo fio da memória dos seres humanos. A complementariedade, segundo Santana, está presente nas noções mais complexas de tempo. Sobre essa ideia, a pensadora explicou que distintos tempos se relacionam e estão acontecendo concomitantemente.

Assim como fez com o conceito de tempo, Santana abordou a questão da memória sob distintas óticas. Dentre as diferentes maneiras de entender a memória, a pensadora mencionou o conceito dos bakongos. Nas palavras de Santana, o filósofo Tiganá Santana entende que tudo vibra memória, linha de força que reúne as temporalidades possíveis.

Após ouvir a complexidade dessas definições, pensei que a cultura, assim como a física quântica sustenta a tese da simultaneidade dos tempos. Entretanto, a teoria quântica 
localiza-se na história recente e o mesmo não pode ser dito de todas as culturas mencionadas por Santana ao longo da conferência.

A palestrante comentou que a memória individual é um ponto de vista sobre a memória coletiva e, ao mesmo tempo, a memória se torna coletiva quando é compartilhada. Santana também explicou que a memória coletiva pode influenciar a memória individual.

A memória, contudo, não é a lembrança completa do tempo passado, mas a organização de fragmentos do pretérito, que se interligam-se intrinsecamente com o presente e o devir.

Segundo a pensadora, a lembrar é um trabalho racional e o partilhar da memória, pelo viés da linguagem, passa pela sensibilidade do ser. Desse modo, é por intermédio da expressão que a memória se torna a ação do presente e os tempos que se entrecruzam. Ao abordar o tema da memória e da linguagem, Santana mencionou o fato de que na cultura bantu, o coração é responsável pelo ato da fala.

Assim como Éclea Bosi, Leda Martins aponta que a memória é expressa por diferentes linguagens: na escrita, na oralidade, nas danças, nos contos, nas canções, no teatro, nos rituais religiosos, nos gestos e nos hábitos, que são técnicas de criação, de transmissão e de reprodução de saberes, não ficando circunscrita aos lugares de memória, como os museus, as bibliotecas, os arquivos, os monumentos oficiais. A memória está inscrita no corpo.

Ao ouvir as falas da Bianca Santana, recordei-me do poema "Vozes-Mulheres", escrito por Conceição Evaristo (2008, p. 10), que me provoca sempre a refletir sobre o fio que me conecta aos meus ancestrais e que ecoa na minha trajetória:

\begin{abstract}
A voz de minha bisavó / ecoou criança / nos porões do navio. / ecoou lamentos / de uma infância perdida. /A voz de minha avó / ecoou obediência / aos brancos-donos de tudo. / A voz de minha mãe / ecoou baixinho revolta /no fundo das cozinhas alheias / debaixo das trouxas / roupagens sujas dos brancos / pelo caminho empoeirado / rumo à favela. / A minha voz ainda / ecoa versos perplexos / com rimas de sangue / e fome. / A voz de minha filha / recolhe todas as nossas vozes /recolhe em si / as vozes mudas caladas / engasgadas nas gargantas. / A voz de minha filha / recolhe em si / a fala e o ato. / O ontem - o hoje - o agora. / Na voz de minha filha / se fará ouvir a ressonância / o eco da vida-liberdade.
\end{abstract}

O conceito de testemunho foi apresentado a partir da perspectiva de Scholastique Mukasonga, Sueli Carneiro, Jane Sharp, Grada Kilomba, bell holks e Jeanne Marie Gagnebin. Todas as referências trazidas por Santana concordam que os africanos escravizados foram impossibilitados de recuperar suas histórias e consequentemente não puderam enterrar seus mortos, e realizar seus ritos. Não há meios de superar a herança da escravidão porque as histórias e os testemunhos de quem vivenciou violências desta natureza não foram devidamente contadas. 
De acordo com Carneiro (2005), as testemunhas da escravidão são sobreviventes de um evento único na história que foi a escravização dos seus antepassados. Além disso, negros e negras sofrem os efeitos do período colonial que ainda persistem em suas memórias, corpos e experiências de vidas (concretas e subjetivas) até os dias atuais. Ao mesmo tempo são portadores da contra-história, narrativas que ressignificam os assujeitamentos e os estereótipos. Nesse sentido, existem uma enorme pluralidade de histórias, que não se referem apenas às dores e à dominação colonial, mas as estratégias e as táticas de resistências de homens e negras na diáspora.

A memória dos negros, de acordo com Santana, deve ser celebrada, uma vez que, mesmo em um cenário adverso, homens e mulheres negros produziram informação e conhecimento.

Quantos saberes e informações produzidos nas lutas para resistir às dominações da colonização foram apagados ou continuam invisíveis na sociedade brasileira? Será que não poderiam nos ajudar a refletir sobre os problemas que assolam a humanidade na contemporaneidade, por exemplo, os causados pelo neoliberalismo, como o aquecimento global, as migrações ou a miséria? O capitalismo que privilegia o individualismo ao coletivo é única alternativa possível de estar no mundo? O que podemos aprender com a sub-humanidade (indígenas e quilombolas), aquela agarrada à natureza, ou até mesmo com os quase humanos, que estão nas periferias e nas favelas brasileiras, como nos lembra Aílton Krenak? Afinal, repensar o projeto colonial também se insere em analisar as exclusões e as explorações causadas pelo capitalismo desenfreado, que pode levar ao fim do mundo.

Santana comentou que há uma corrente de pensamento que insiste no fato de que os documentos relacionados a escravização negra no Brasil foram destruídos. Sobre esse tema, a pensadora mencionou que, em quatorze de dezembro de 1890, o ministro da fazenda Rui Barbosa assinou um documento em que a república era "obrigada a destruir esses vestígios por honra da pátria em homenagem aos deveres de fraternidade e solidariedade para com a grande massa de cidadãos que a abolição do elemento servil entraram em comunhão brasileira". Como colocou Santana, a fala de Rui Barbosa não visava outra coisa além de proteger o Estado do pagamento de indenizações a fazendeiros que seriam prejudicados pela abolição.

No entanto, Santana destacou que, devido a extensão territorial do Brasil, essa ordem não foi plenamente aplicada e uma grande quantidade de instituições ainda possuem documentos sobre este tema. Santana chamou atenção para a importância da realização de pesquisas sobre esses documentos como possibilidade de reconstituir as histórias das negras e dos negros que foram escravizados e seus descendentes. Em outras palavras, para que pesquisadoras e pesquisadores desenterrarem o passado traumático da escravidão, organizando os documentos encontrados, reconstruindo o mosaico incompleto da história da diáspora negra no país e visibilizando tais informações. Acredito que as memórias que ecoam o silenciamento ancestral nos afrodescendentes também podem corroborar para a compreender os documentos 
que podem estar arquivados e esquecidos nos acervos de igrejas, cartórios, dioceses e fazendas.

Sobre a importância de análise desses documentos, Santana mencionou que no ano de 1977 Abdias Nascimento preparou um discurso que seria proferido no segundo festival mundial de artes e culturas negras e africanas realizado na Nigéria. Em seu discurso, Abdias fez uma série de recomendações ao governo brasileiro. Entretanto, ele foi proibido de discursar naquele evento. Tempos depois o discurso de Abdias foi publicado como ensaio. Santana menciona o que estava escrito nesse documento, a saber: "este colóquio recomenda que o governo brasileiro localize e publique documentos e outros fatos e informações possivelmente existentes em arquivos privados, cartórios, arquivos de câmara municipal de velhas cidades do interior referentes ao tráfego negreiro, a escravização e a abolição. Em resumo, qualquer dado que possa ajudar a esclarecer e aprofundar a compreensão da existência do africano escravizado e seus descendentes".

Santana terminou sua apresentação dizendo que os documentos citados por Abdias existem e esperam por pesquisas.

Após a fala de Santana percebi que desconheço uma grande parte das culturas apresentadas por ela. Lamento a mim mesma por isso. Sempre ouvi dizer que a arte antecede a ciência, a exemplo disso pode-se mencionar Sófocles que, em sua obra Édipo Rei, previu o que muito tempo depois seria legitimado como ciência por Freud. Há seis anos, eu também desconhecia, foram as minhas pesquisas étnicos-raciais que me levaram a conhecer um pouco do enorme universo de saberes e de culturas produzidas pelos meus ancestrais. Para mim, até 2014, não existiam Aqualtune, Dandara, Carolina Maria de Jesus, Lélia Gonzalez, Sueli Carneiro, Beatriz Nascimento e outras mulheres e homens que, hoje, me fazem ter muito orgulho das minhas raízes africanas e afro-brasileiras. "Nossos passos veem de longe", diz Jurema Werneck e eu sempre reafirmo para longe iremos. Nilma Lino Gomes e Kabengele Munanga destacam que, para os afrodescendentes, o orgulho da origem africana está diretamente interligado pelo conhecimento das culturas e das histórias africanas e afro-brasileiras. Quantos atrasos e perdas científicas e culturais não custou à humanidade o silenciamento das culturas de matrizes africanas? O mesmo podemos dizer dos povos indígenas.

Como meu trabalho dentro do campo da Ciência da Informação está posicionando-se ou sendo indiferente à questão da cultura do silenciamento? Não ter um posicionamento diante de questões como essa não nos torna um algoz de nossos próprios tempos, histórias e memórias individuais? Talvez, seria mais adequado, após acompanhar a fala de Santana, dizer que não há distinção entre tempo mitológico e tempo histórico, entre o individual e o coletivo... 


\section{A mediação de Cayo Honorato7}

A intervenção de Cayo Honorato baseou-se nas reflexões apresentadas por Moura e Santana durante o encontro "Decolonilalidade e Ciência da Informação: veredas dialógicas" e em estudos feitos a partir da obra acadêmica das palestrantes. Ao dirigirse a Moura, o mediador formulou seu questionamento levando em consideração o conceito de interseccionalidade e de reparação taxonômica.

O conceito de interseccionalidade, trazido à luz por Honorato, foi desenvolvido por Kimberlé Crenshaw e consiste em demonstrar que que as dimensões de raça, de gênero e de exploração de classe, por exemplo, operam de forma articulada e estruturam as experiências de vida das mulheres negras. Dessa forma, as opressões se intercruzam, ou seja, não podem ser analisadas separadamente e uma dimensão não é mais ou menos opressiva que a outra, já que agem juntas. A teoria de Crenshaw indica que as vulnerabilidades interseccionais influenciam negativamente a garantia de direitos humanos e funciona como uma ferramenta de análise. É importante ressaltar que a ideia de interseccionalidade das opressões, contudo, já fazia parte do arcabouço teórico desenvolvido por intelectuais e feministas negras, como Lélia Gonzalez, Sueli Carneiro, Luiza Bairros, Patricia Hill Collins, Angela Davis e bell hooks. A reparação taxonômica, por sua vez, abordada por Honorato na perspectiva de Melissa Adler, que é mobilizada por Moura em seus trabalhos acerca dos sistemas de organização do conhecimento (SOCS), pode ser entendida como a possibilidade de agir no campo da semântica e da representação revelando o caráter arbitrário de determinados termos.

Honorato destaca que tanto a reparação taxonômica como a interseccionalidade despertam e ampliam a lucidez diante de propostas opressoras. Contudo, na tentativa de classificar pluralidades, ambos os conceitos podem esbarrar em questões relativas às representações.

O comentário do mediador dá maior relevo ao risco de serem gerados epifenômenos dentro do sistema da interseccionalidade. Nas palavras de Honorato, os limites da representação são também os limites da interseccionalidade. Dito isso, Moura foi convocada a responder como o mesmo problema, isto é, os limites dos sistemas de representação, é tratado no âmbito do exuzilhamento.

Para Santana, o mediador perguntou sobre a diferença entre o tempo histórico e o tempo cosmológico. Honorato diz suspeitar da nomenclatura que escolheu para formular sua indagação e propôs a reformulação da mesma questão utilizando outros termos. Assim, dito de outro modo, o mediador indagou sobre a possibilidade de considerar o tempo ocidental em oposição ao tempo iorubá ou bakongo? Não satisfeito com a reformulação da questão, Honorato mencionou o fato de Muniz Sodré

\footnotetext{
7 Cayo Honorato é Professor Adjunto no Departamento de Artes Visuais (VIS) do Instituto de Artes (IdA) da Universidade de Brasília (UnB) e possui bacharel em Artes Visuais, mestrado em Educação pela Faculdade de Educação (FE) da Universidade Federal de Goiás (UFG) e doutorado em Educação pela Faculdade de Educação (FE) da Universidade de São Paulo (USP).
} 
utilizar o termo temporalidade mítica no lugar de tempo cosmológico. Em suma, Honorato desejava saber como esses distintos tempos se exuzilham.

Moura foi a primeira a responder as questões colocadas por Honorato. Ela iniciou sua fala relatando sua dedicação à questão da representação no campo da metodologia da Ciência da Informação desde o período em cursava a graduação. Segundo Moura, durante muito tempo, a Ciência da Informação não dialogou com a questão da representação, essa postura, resultou na criação de instrumentos legitimados de informação que flertam com valores coloniais. Moura sugeriu que essa falha deve ser revertida por intermédio da ação na exuzilhada. Ao operar pelo viés do exuzilhamento, o campo da Ciência da Informação pode dar voz a outros saberes, corporeidades e fazeres.

Pela perspectiva de Moura, a teoria de Crenshaw alerta-nos para o fato de os seres humanos serem atravessados por diversas e diferentes dimensões sociais (raça, gênero, orientação sexual, religião, dentre outras), isso comprova que é impossível que sejamos enquadrados em definições permanentes. O resultado dessa impossibilidade de enquadramento exige que sejam criados lugares de trocas, compartilhamentos e diálogos. Moura acredita que é importante criar espaços “desarmados" e, a exemplo disso, existe a exuzilhada. A interseccionalidade pode ser entendida, segundo Moura, como o reconhecimento da pluralidade de discursos. Quando essa diversidade não é reconhecida, explicou a professora, sujeitos, saberes, culturas e cosmovisões são silenciados e invisibilizados. A exuzilhada é o lugar onde acontece o encontro entre essas vozes. Em outras palavras, é ali que os saberes e os conhecimentos sobre os mais variados temas e objetos, que produzidos por sujeitos rarefeitos ou não, encontram-se, dialogam, divergem e intercambiam-se.

Moura reconheceu os limites da reparação taxionômica, e comentou que a ação de nomear é resultado de um processo de poder. Sobre esse tema, a professora pensa que, é necessário analisar, como um determinado conhecimento é produzido e nomeado. Nós, pesquisadoras e pesquisadores em Ciência da Informação, enquanto produtores, organizadores, disseminadores e, principalmente legitimadores de informação e de conhecimento, precisamos compreender e estar diariamente atentos diariamente para os atravessamentos que acontecem na exuzilhada, como bem observou a professora, que fez alerta especial aos desenvolvedores dos sistemas de sOCs.

Moura terminou sua resposta alertando que é preciso reconhecer o poder dos processos informacionais e levar a ideia de exuzilhada para dentro do campo da Ciência da Informação. Só assim, segundo a professora, é possível garantir o não silenciamento de vozes e a inclusão de saberes.

Refletindo sobre a fala de Moura, creio que todos os conceitos apresentados por ela e por Honorato poderiam ser pensados a partir da ideia de uma ação contínua. Penso que o tema dos limites da representação dentro de contextos decoloniais merecem vigilância incansável para que não incorram no risco de se tornarem o próprio inimigo que combatem. As perguntas que se colocam aqui são: seriam os conflitos gerados 
pelos limites da representação responsáveis por inaugurarem um lugar "desarmado"? Quais conflitos cabem nas exuzilhadas?

Santana, ao responder o questionamento de Honorato, explicou que o tempo histórico faz parte do tempo mítico. É no tempo histórico que as pessoas vivem a experiência do tempo mítico. O tempo cíclico pode trazer sentido para o tempo histórico. $\mathrm{O}$ encontro desses dois tempos pode trazer sentido para a nossa existência, conectando o presente ao passado e ao futuro. Ainda sobre esse tema, Santana mencionou seu desejo de querer romper com alguns tempos cíclicos que ameaçam a democracia no Brasil.

A dificuldade de localizar registros relacionados a escravidão foi outro assunto abordado por Santana. A questão da escassez de documentos sobre a história dos negros foi tratada por Santana pela ideia de epistemicídio da informação. Baseada no pensamento de Sueli Carneiro, Santana explicou o epistemicídio da informação a partir de três aspectos, são eles: em primeiro lugar, o epistemicídio ocorre porque aquilo que o não-branco produz não é reconhecido como conhecimento; em segundo lugar, o sujeito não-branco não é reconhecido como um produtor de conhecimento; e, em terceiro lugar é negado às pessoas negras a possibilidade de produzir saber. Nessa perspectiva, a pensadora afirmou que contestar a existência, mesmo que escassa, dos documentos relativos à escravidão é um epistemicídio.

Santana elencou os valores que sustentam a lógica do epistemicídio e, posteriormente, sugeriu como esse cenário pode ser revertido. $O$ trabalho de pesquisa e a organização de acervos são, para a pensadora, fundamentais para combater a perversidade desse sistema.

Neste ponto, chama-me a tenção o fato de Santana estar localizando o problema do epistemicídio e propondo uma solução para ele. Não menos importante é dizer que Santana dá um passo ainda mais adiante e, a partir da pesquisa que atualmente está desenvolvendo sobre a genealogia da família de da Sueli Carneiro, a pensadora colocou em prática, aquilo que ela indica como um antídoto ao epistemicídio,

Após a resposta de Santana, o mediador compartilhou perguntas elaboradas pelos ouvintes do evento.

Ao responder à pergunta do ouvinte Fabrício Silveira, a professora Moura explicou a ideia de lócus fraturados na Ciência da Informação. Esse conceito, segundo a pensadora, pode ser entendido como a hierarquização da norma e dos valores que constituem o campo da Ciência da Informação e a obediência acrítica aos processos que as configuram.

Ambas as palestrantes foram questionadas por outro ouvinte. Marco Antonio de Almeida perguntou sobre a possibilidade de espaço para narrativas dentro do campo da Ciência da Informação. 
Moura respondeu a essa questão dizendo que a Universidade Federal de Minas Gerais (UFMG) se dedica ao reconhecimento dos saberes tradicionais de maneira contundente e mencionou que há cursos e pesquisas relativos ao tema que estão sendo desenvolvidos dentro da UFMG. "Se não tem, precisa ter", destacou a professora ao concluir sua participação. Por sua vez, Santana respondeu à questão do ouvinte comentando que a divisão entre uma narrativa racional e outra não racional faz pouco sentido em contextos que não estão ancorados em tradições não hegemônicas. Santana encerrou sua fala dizendo que não defende a negação da ciência, mas enfatiza a urgência em incluir outros saberes, cosmovisões e sujeitos ao campo. Para finalizar a fala, a pensadora evoca Exu, afirmando que a $\mathrm{Cl}$ precisa se aproximar da exuzilhada.

O questionamento do Marco Antonio de Almeida me deixou reflexiva também e penso que as narrativas e as memórias têm uma dimensão heurística, que podem reescrever a história do Brasil, a partir de outros sujeitos que não o "eu hegemônico", além de visibilizar saberes que permitam analisar os problemas contemporâneos da humanidade, considerando sempre, é claro, a encruzilhada de conhecimentos e de culturas.

Creio que esse último comentário de Santana levanta uma das questões mais delicadas para uma mente em processo de desconstrução colonial como a minha. Explico-me. Tenho dificuldade de não desconfiar da fusão entre conhecimento e fé, materialidade e imaterialidade.

Acredito que isso faz parte do processo de desconstrução. No entanto, a ideia é aproximar o conhecimento racional, das luzes do iluminismo, com os outros saberes, que não tem na razão necessariamente sua fonte primeira. $\mathrm{Na}$ exuzilhada, tais conhecimentos podem se encontrar, intercambiar, sem apaziguar os conflitos, o que pode ser extremamente frutífero para pensarmos uma ciência - verdadeiramente brasileira. Quando falamos que a cultura afro-brasileira é um entre-lugares, o Brasil não foge disso também.

Assim como Santana e Moura, não creio que o caminho seja negar essas narrativas e saberes populares, mas penso que é necessário manter vigilância quando apoiamos propostas de aproximação entre a ciência e essas narrativas. Confio no fato de essas narrativas trazerem conflitos inéditos e importantes para o avanço da humanidade em diversos segmentos (na medicina, na tecnologia etc.), porém assumo minha intranquilidade quanto a possibilidade de que esses conflitos sejam resolvidos e se tornem discursos hegemônicos. Desculpo-me publicamente por isso.

Quijano (1992, 2005), Mignolo (2017), Amin (1989) afirmam que estruturação da ciência moderna omitiu os intercâmbios culturais e de saberes entre europeus, asiáticos e africanos, que aconteceram antes do Período das Luzes. O conhecimento eurocêntrico colonizou outras formas de saber e, apesar no nome, não representa sequer os saberes de todos os povos e os sujeitos da Europa. O filósofo peruano destaca que tal iniciativa foi essencial para legitimar as explorações e as dominações dos povos africanos e indígenas, a partir da classificação de raça dos "Outros", os não-europeus. Dessa 
forma, o conhecimento eurocêntrico se tornou hegemônico, pois havia interesse de conquistar territórios e dominar populações, ou seja, foi instrumentalizado para estruturar os modos pré-capitalistas e para a reprodução do capital. Os saberes tradicionais (africanos, afro-brasileiros, periféricos e indígenas) não têm a lógica de dominação, mas de "resolver" problemas locais ou ocasionados pelo colonialismo, como o apagamento de memórias e de narrativas e a invisibilização de saberes e de sujeitos.

Não menos importante é dizer que confio nos conflitos que podem ser gerados a partir dessas narrativas e encerro minha reflexão agradecendo imensamente a Thais Pereira por me ajudar neste processo de desconstrução. Agradeço imensamente a Naiane Sanchez por ter me feito o convite que me ajudou no meu processo de desconstrução que é diário. Por fim, a minha intervenção nesse texto-performance, a partir da exuzilhada, inspira-me ainda mais a refletir sobre as minhas angústias para encontrar novas formas de produzir conhecimento.

\section{REFERÊNCIAS}

AMIN, Samir, 1989. El Eurocentrismo. Crítica de uma ideología. Mexico: Siglo Editores.

BHABHA, Homi K., 2013. O local da Cultura. Belo Horizonte: Editora UFMG.

CARNEIRO, Sueli, 2011. Racismo, Sexismo e Desigualdade no Brasil. São Paulo: Selo Negro.

CARNEIRO, Sueli, 2005. A construção do outro como não-ser como fundamento do ser. Tese (Doutorado em Educação) Universidade de São Paulo. São Paulo.

CARNEIRO, Sueli, 2018. Escritos de uma vida. Belo Horizonte: Editora Letramento.

COLLINS, Patricia Hill e BILGE, Sirma, 2017. Intersectionality. Cambridge: Polity.

CRENSHAW, Kimberlé, 2017. Mapping the Margins: Intersectionality, Identity Politics, and Violence against Women of Color. Stanford Law Review. 2017, vol. 43, no. 6, 1991. p. 1.241-99. Disponível em < https://negrasoulblog.files.wordpress.com/2016/04/mapping-the-marginsintersectionality-identity-politics-and-violence-against-women-of-color-kimberlecrenshaw1.pdf >

EVARISTO, Conceição, 2008. Vozes-Mulheres. In: Poemas da recordação e outros movimentos. Belo Horizonte: Nandyala.

FOUCAULT, Michel, 2015. Microfísica do Poder. Rio de Janeiro: Editora Paz e Terra.

GOMES, Nilma Lino, 2005. Alguns termos e conceitos presentes no debate sobre relações raciais no Brasil: uma breve discussão. In: BRASIL. Educação Anti-racista: 
caminhos abertos pela Lei federal n ${ }^{\circ}$ 10.639/03. Brasília, MEC, Secretaria de educação continuada e alfabetização e diversidade.

KILOMBA, Grada, 2016. Quem pode falar?. 12 janeiro 2016. [Acesso em 9 outubro 2021].Disponível em: http://www.pretaenerd.com.br/2016/01/traducao-quem-podefalar-grada-kilomba.html

KRENAK, Ailton, 2019. Ideias para adiar o fim do mundo. São Paulo: Companhia das Letras.

MARTINS, Leda, 2002. Performances do tempo espiralar. In: Performance, exílio, fronteiras; errâncias, territórios e textuais. Belo Horizonte: Departamento de Letras Românticas, Faculdade de Letras / UFMG: Poslit.

MARTINS, Leda, 2003. Performances da Oralitura: corpo lugar de memória. In: Revista do programa de Pós-Graduação em Letras, no. 26. Língua e Literatura: Limites e Fronteiras.

MIGNOLO, Walter D. Colonialidade. O lado mais escuro da modernidade. In: Revista Brasileira de Ciências Sociais. 2017. vol. 32 no. 94.

MOURA, Maria Aparecida, 2018. Organização social do conhecimento e performatividade de gênero: dispositivos, regimes de saber e relações de poder. In: Liin em Revista, Rio de Janeiro, vol.14, no.2, p. 118-135.

MUNANGA, Kabengele, 1996. As facetas de um racismo silenciado. In: Raça e Diversidade. São Paulo: Edusp/Estação.

PRANDI, Reginaldo, 2001. Mitologia dos Orixás. São Paulo: Companhia das Letras.

QUIJANO, Aníbal. Colonialidade do poder, eurocentrismo e América Latina. In: A colonialidade do saber: eurocentrismo e ciências sociais. Perspectivas latinoamericanas, Buenos Aires, 2005.

QUIJANO, Aníbal, 1992. Colonialidad Y Modernidad/racionalidade. In: Perú Indígena, vol. 13, no. 29, Lima.

SANTOS, Tiganá Santana Neves, 2019. A cosmologia africana dos bantu-kongo por Bunseki Fu-Kiau: tradução negra, reflexões e diálogos a partir do Brasil. Tese Doutorado em Letras. Faculdade de Filosofia, Letras e Ciências Humanas, da Universidade de São Paulo. 